\title{
Identifikasi Kandungan Saponin dalam Ekstrak Kamboja Merah (Plumeria rubra L.) dan Daya Surfaktan dalam Sediaan Kosmetik
}

\author{
Identification of Saponin Content in Red Frangipani (Plumeria rubra L.) Extract and \\ Surfactant Potency in Cosmetic Preparations \\ Fulka Nurzaman $^{1 *}$, Joshita Djajadisastra ${ }^{2}$, Berna Elya ${ }^{3}$ \\ ${ }^{1}$ Program Magister Herbal, Fakultas Farmasi, Universitas Indonesia, Depok, Indonesia \\ ${ }^{2}$ Departemen Farmasetika, Fakultas Farmasi, Universitas Indonesia, Depok, Indonesia \\ ${ }^{3}$ Departemen Fitokimia, Fakultas Farmasi, Universitas Indonesia, Depok, Indonesia \\ *Email: nusaherbsindns@gmail.com
}

Direvisi : 15 April 2018

Disetujui: 10 Juli 2018

\begin{abstract}
Abstrak
Saponin merupakan salah satu golongan senyawa pada bahan alam yang mempunyai sifat ampifilik serta dapat menurunkan tegangan permukaan. Penurunan tegangan permukaan disebabkan karena adanya senyawa sabun yang dapat merusak ikatan hidrogen pada air. Kamboja merah (Plumeria rubra) diketahui memiliki kandungan saponin. Penelitian ini bertujuan untuk mengidentifikasi kandungan saponin ekstrak kamboja merah yang memiliki sifat menurunkan tegangan permukaan. Bagian tanaman kamboja merah (bunga, daun, dan batang) diekstraksi menggunakan lima macam pelarut. Masing-masing ekstrak yang diperoleh diuji kandungan saponin secara kualitatif. Uji tegangan permukaan dilakukan pada ekstrak kamboja merah yang memiliki busa tertinggi. Hasil uji kualitatif saponin menunjukkan bahwa ekstrak air bunga, daun, dan batang kamboja merah memiliki kandungan saponin tertinggi dibandingkan ekstrak pelarut lain. Kandungan saponin dalam ekstrak air kamboja merah bagian daun, batang, dan bunga dapat menurunkan tegangan permukaan dengan hasil terbaik diperoleh dari bagian bunga dengan nilai Critical Micelle Concentration (CMC) sebesar 8,61\%.
\end{abstract}

Kata kunci: Saponin; Kamboja; Tegangan permukaan

\begin{abstract}
Saponin is one group of compounds contained in natural materials that have amphifilic properties and can reduce surface tension. The reduction of surface tension caused by a soap compound (Latin = sapo) that can disrupt hydrogen bonds in water. Red frangipani plant (Plumeria rubra) is known to have saponin content. The research objectives were to identify the saponin content of red frangipani plant extract (Plumeria rubra) which has the properties of reduction the surface tension. Part of red frangipani plant (flowers, leaves and stems) is extracted using five kinds of solvents. Each of the extracts obtained was then tested for saponin content qualitatively. Extract from each part of plant (flower, leaf, and stem) which have the highest foam is selected then tested surface tension using surface tensionmat equipment. The result of qualitative saponin test showed that flower, stem and flower extract of red frangipani with aqua demineralisata solvent had the highest saponin content compared to extract with other solvent. The content of saponins in plumeria rubra extract both from the leaves, stems and flowers can decrease the surface tension with the best results obtained from the flower extract with the value of Critical Micelle Concentration (CMC) at $8.61 \%$.
\end{abstract}

Keywords: Saponin; Frangipani; Surface tension 


\section{PENDAHULUAN}

Saponin merupakan suatu glikosida yang memiliki aglikon berupa sapogenin. Saponin dapat menurunkan tegangan permukaan air, sehingga akan mengakibatkan terbentuknya buih pada permukaan air setelah dikocok. Sifat ini mempunyai kesamaan dengan surfaktan. Penurunan tegangan permukaan disebabkan karena adanya senyawa sabun yang dapat merusak ikatan hidrogen pada air. Senyawa sabun ini memiliki dua bagian yang tidak sama sifat kepolarannya. ${ }^{1}$ Struktur kimia saponin merupakan glikosida yang tersusun atas glikon dan aglikon. Bagian glikon terdiri dari gugus gula seperti glukosa, fruktosa, dan jenis gula lainnya. Bagian aglikon merupakan sapogenin. Sifat ampifilik ini dapat membuat bahan alam yang mengandung saponin bisa berfungsi sebagai surfaktan.

Surfaktan adalah bahan yang umum dipakai dalam sediaan sabun. Surfaktan merupakan suatu molekul yang sekaligus memiliki gugus hidrofilik dan gugus lipofilik sehingga dapat mempersatukan campuran yang terdiri dari air dan minyak. Molekul surfaktan memiliki bagian polar yang suka akan air (hidrofilik) dan bagian non polar yang suka akan minyak/lemak (lipofilik). Bagian polar molekul surfaktan dapat bermuatan positif, negatif atau netral. $^{2}$

Kosmetika pembersih adalah kosmetik perawatan utama yang digunakan untuk memelihara kesehatan kulit dan adneksanya agar tetap sehat serta dapat merawat kulit yang kurang sehat agar menjadi sehat. Berbagai produk pembersih pada umumnya mengandung sodium lauryl sulfate (SLS) atau sodium laureth sulfate (SLES). Keduanya merupakan surfaktan dan emulsifier yang berfungsi mengikat lemak dan kotoran. Selain mengikis minyak, kotoran, dan lemak, SLS dan SLES berfungsi sebagai foaming agent. Pemakaian produk SLS dan SLES dosis tinggi berkepanjangan bisa memicu iritasi. Keluhan terkait iritasi itu bisa berupa kulit kering, bersisik, gatal, hingga ruam merah, dan jika memiliki kulit sensitif dapat muncul reaksi yang lebih kuat. SLS dan SLES merupakan surfaktan dari turunan minyak bumi dan gas alam yang setelah digunakan dapat menjadi limbah yang sukar terdegradasi sehingga menimbulkan pencemaran lingkungan.

Tanaman kamboja (Plumeria) berasal dari Meksiko, Amerika Tengah yang kemudian menyebar ke daerah tropis. Nama Plumeria diberikan untuk menghormati Charles Plumier (1646-1706) pakar botani dari Perancis. ${ }^{3}$ Tanaman kamboja mulai dari akar, batang, getah, daun, kulit batang, dan bunga memiliki banyak manfaat. Akar kamboja dapat digunakan untuk mengobati kencing nanah, daun dapat mengobati bisul bernanah, kulit batang untuk menyembuhkan tumit pecah-pecah, getah kamboja dapat digunakan sebagai pengurang rasa sakit akibat gigi berlubang, gusi bengkak, dan mematangkan bisul. ${ }^{4}$

Kamboja juga merupakan tanaman obat dan dibudidayakan di kebun seluruh India sebagai pohon hias serta banyak digunakan dalam wewangian. ${ }^{5}$ Bunga kamboja merah mengandung saponin dan glikosin dengan studi toksisitas akut memberikan hasil aman sampai dosis $2000 \mathrm{mg} / \mathrm{kgBB}$ tanpa ada kondisi letal pada hewan uji. Hasil penelitian menunjukkan $\mathrm{LD}_{50}>2000$ $\mathrm{mg} / \mathrm{kgBB} .^{6,7}$

Penapisan fitokimia ekstrak daun kamboja merah mendeteksi kadar saponin yang cukup tinggi dan memiliki aktivitas antiinflamasi dan antelmintik. ${ }^{8}$ Saat ini tanaman kamboja telah digunakan sebagai bahan baku dupa, aroma terapi, kosmetika, dan minuman kesehatan. ${ }^{4}$

Akar kamboja merah mengandung senyawa plumericine, $\quad \beta$-dihydroplumericin, $\quad$ isoplumericin, $\quad \beta$ dihydroplumericin acid, fulvoplumerine, dan plumeride. Rubrinol merupakan triterpenoid yang berperan sebagai antibakteri bersama teraxasteryl acetate, lupeol, stigamateol, oleanolic acid diisolasi dari kulit kayu kamboja. Bunga 
kamboja memiliki kandungan senyawa 1 diethoxyethane, benzaldehyde, geraniol, citral, methylbenzoate, nerolidols, naphathelene, linalool, banzylbenzoate, serta methyl salicylate. ${ }^{9}$

Batang kamboja merah mengandung scopoletin, $\beta$-sitosterol, plumieride, fulvoplumerin. Sedangkan akarnya mengandung plumericine, $\beta$-dihydroplumericin, $\quad$ isoplumericin, $\quad \beta$ dihydroplumerinic acid, fulvoplumerin, dan plumeride. ${ }^{10}$

Bahan alam dengan kadar saponin tinggi diharapkan dapat menggantikan fungsi surfaktan dengan tingkat iritasi lebih rendah serta ramah lingkungan dalam sediaan pembersih. Beberapa penelitian yang telah dilakukan terhadap tanaman kamboja merah menunjukkan bahwa tanaman tersebut secara fitokimia mengandung saponin yang bisa menimbulkan busa secara kualitatif. Penelitian ini bertujuan untuk mengidentifikasi kandungan saponin ekstrak tanaman kamboja merah yang memiliki sifat menurunkan tegangan permukaan.

\section{METODE}

Desain penelitian ini adalah studi eksperimental laboratorium. Kegiatan yang dilakukan meliputi pembuatan simplisia dan ekstraksi kamboja merah (Plumeria rubra) serta uji kualitatif saponin dan uji tegangan permukaan dari ekstrak tanaman kamboja merah (Plumeria rubra). Penelitian dilakukan di Laboratorium Fitokimia, Fakultas Farmasi, Universitas Indonesia.

\section{Alat dan bahan}

Alat yang digunakan dalam penelitian ini antara lain timbangan (Kenko), lemari pengering (Memmert), grinder, maserator, rotary evaporator, lemari pendingin, rotary shaker, freeze dryer, Surface tensiomat (Cole Parmer ${ }^{\circledR}$ Model 21), pH meter (Ohaus 3100). Bahan yang digunakan adalah bagian tanaman kamboja merah meliputi bunga, daun, dan batang yang diperoleh dari TPU Kramat Kelurahan Sukatani, Depok, akua demineralisasi (Brataco), etanol 96\% (Brataco), propilen glicol (Dow chemical), asam klorida (Merck), pereaksi Liebermann-Burchard, dan kloroform (Mallincrodt).

\section{Prosedur kerja}

\section{Preparasi dan pembuatan simplisia}

Simplisia yang digunakan adalah bagian bunga, daun, dan batang tanaman kamboja merah. Bagian tanaman kamboja merah kemudian dideterminasi atau diidentifikasi di Herbarium LIPI Cibinong dan telah diperoleh hasil yang sesuai dengan Nomor 2288/IPH.1.01/If.07/ $\mathrm{X} / 2017$. Masing-masing bagian tanaman tersebut dicuci bersih dan dipotong-potong kemudian dikeringkan menggunakan lemari pengering. Selanjutnya bagian tanaman dihaluskan menggunakan mesin penggiling hingga menjadi serbuk. Simplisia disimpan dalam wadah kering tertutup rapat dalam ruangan yang terlindung dari cahaya matahari.

\section{Ekstraksi tanaman kamboja merah}

Ekstraksi kamboja merah dilakukan secara maserasi sesuai dengan prosedur Farmakope Herbal Indoensia. Pemilihan jenis pelarut dilakukan berdasarkan sifat saponin yang dapat larut dalam pelarut polar sehingga proses ekstraksi dilakukan menggunakan pelarut polar dan campurannya meliputi air, etanol, dan propilen glikol. ${ }^{11}$ Serbuk simplisia dari masing masing bagian tanaman yaitu bunga, daun, dan bagian batang diekstraksi secara maserasi menggunakan 5 jenis pelarut dengan perbandingan simplisia dan pelarut (1:10) (Tabel 1).

Serbuk simplisia ditimbang sebanyak 50 gram, kemudian dimasukkan ke dalam bejana maserator. Pelarut ditambahkan sebanyak 500 gram. Perendaman dilakukan selama 6 jam sambil sekalisekali diaduk, kemudian didiamkan selama 18 jam. Maserat dipisahkan dengan pengendapan, dekantasi, dan filtrasi. 
Proses penyarian diulangi dengan jenis dan jumlah pelarut yang sama, sehingga diperoleh jumlah maserat kurang lebih dua kalinya. Semua maserat terkumpul dievaporasi pada suhu $65^{\circ} \mathrm{C}$. Untuk pelarut yang menggunakan air $100 \%$ evaporasi dilakukan menggunakan freeze dryer. Maserat dievaporasi hingga diperoleh ekstrak cair dengan bobot 100 gram. Jika setelah ditimbang bobot kurang dari 100 gram, maka disetarakan dengan menggunakan pelarut yang sama hingga bobotnya 100 gram. Bobot ekstrak ini ditetapkan berdasarkan batasan mengenai ekstrak cair yang dibuat sedemikian rupa sehingga 1 bagian simplisia sesuai dengan 2 bagian ekstrak cair. ${ }^{12}$ Ekstrak cair tersebut kemudian dimasukkan ke dalam wadah tertutup dan diberikan label sesuai kode simplisia dan pelarut. Masing-masing ekstrak tanaman kamboja merah (Plumeria rubra) diukur $\mathrm{pH}$ nya menggunakan $\mathrm{pH}$ meter dan diamati organoleptisnya (warna, rasa, dan bau).

\section{Uji kualitatif saponin}

Masing-masing ekstrak kamboja merah (Plumeria rubra) dilakukan uji kualitatif saponin menggunakan uji busa. Ekstrak kamboja merah diencerkan dengan akua demineralisata dengan perbandingan 1:1, kemudian dikocok selama 10 menit. Kandungan saponin ditunjukkan dengan busa yang stabil selama 30 menit. $^{13}$ Tinggi busa masing-masing ekstrak diukur menggunakan penggaris. Ekstrak yang menghasilkan busa tertinggi kemudian dilakukan uji lanjutan yaitu uji tegangan permukaan.

\section{Pengukuran tegangan permukaan}

Uji tegangan permukaan ekstrak kamboja merah dilakukan dengan metode cincin du Noüy menggunakan alat Surface Tensiomat. Ekstrak yang diukur tegangan permukaan dilarutkan dengan akua demineralisata sehingga diperoleh konsentrasi larutan ekstrak 0\%, 2\%, 5\%, $10 \%, 15 \%, 20 \%, 30 \%$ dan 50\%. Skala yang ditunjukkan alat merupakan nilai tegangan permukaan larutan ekstrak. ${ }^{14}$

\section{HASIL DAN PEMBAHASAN}

Ekstraksi dilakukan secara maserasi dengan membandingkan tiga jenis bagian dari tanaman kamboja merah yaitu bagian bunga, daun, dan batang menggunakan 5 jenis pelarut. Metode maserasi dilakukan sesuai dengan prosedur Farmakope Herbal Indonesia. Hasil karaterisasi ekstrak kamboja merah terdapat pada tabel 2.

Seluruh ekstrak ditentukan kandungan saponin melalui uji busa. Tabel 3 menunjukkan hasil uji busa dari ekstrak kamboja merah.

Tabel 1. Pelarut yang digunakan dalam ekstraksi

\begin{tabular}{lcl}
\hline Jenis Simplisia & Kode Sample & \multicolumn{1}{c}{ Pelarut Ekstrak } \\
\hline Bunga Kamboja & A1 & Air \\
& A2 & Air : Etanol 96\% (70:30) \\
& A3 & Air : Etanol 96\% (50:50) \\
& A4 & Air : Etanol 96\% (30:70) \\
& A5 & Air : Etanol 96\% : Propilenglikol (40:30:30) \\
\hline Daun Kamboja & B1 & Air \\
& B2 & Air : Etanol 96\% (70:30) \\
& B3 & Air : Etanol 96\% (50:50) \\
& B4 & Air : Etanol 96\% (30:70) \\
& B5 & Air : Etanol 96\%: Propilenglikol (40:30:30) \\
\hline Batang Kamboja & C1 & Air \\
& C2 & Air : Etanol 96\% (70:30) \\
& C3 & Air : Etanol 96\% (50:50) \\
& C4 & Air : Etanol 96\% (30:70) \\
& C5 & Air : Etanol 96\%: Propilenglikol (40:30:30) \\
\hline
\end{tabular}


Tabel 2. Hasil Karakterisasi Ekstrak Kamboja merah

\begin{tabular}{|c|c|c|c|c|c|}
\hline \multirow{2}{*}{ Kode Ekstrak } & \multicolumn{5}{|c|}{ Hasil } \\
\hline & Bentuk & Bau & Rasa & Warna & pH \\
\hline A1 & Ekstrak Cair & Khas & Pahit & Kecoklatan & 4,61 \\
\hline A2 & Ekstrak Cair & Khas & Pahit & Kecoklatan & 5,42 \\
\hline A3 & Ekstrak Cair & Khas & Pahit & Kecoklatan & 6,06 \\
\hline A4 & Ekstrak Cair & Khas & Pahit & Kecoklatan & 6,13 \\
\hline A5 & Ekstrak Cair & Khas & Pahit & Kecoklatan & 5,72 \\
\hline B1 & Ekstrak Cair & Khas & Pahit & Kecoklatan & 5,21 \\
\hline $\mathrm{B} 2$ & Ekstrak Cair & Khas & Pahit & Kecoklatan & 5,53 \\
\hline B3 & Ekstrak Cair & Khas & Pahit & Kecoklatan & 5,84 \\
\hline B4 & Ekstrak Cair & Khas & Pahit & Kecoklatan & 6,42 \\
\hline B5 & Ekstrak Cair & Khas & Pahit & Kecoklatan & 6,03 \\
\hline $\mathrm{C} 1$ & Ekstrak Cair & Khas & Pahit & Kecoklatan & 5,08 \\
\hline $\mathrm{C} 2$ & Ekstrak Cair & Khas & Pahit & Kecoklatan & 6,23 \\
\hline C3 & Ekstrak Cair & Khas & Pahit & Kecoklatan & 6,82 \\
\hline $\mathrm{C} 4$ & Ekstrak Cair & Khas & Pahit & Kecoklatan & 6,91 \\
\hline $\mathrm{C} 5$ & Ekstrak Cair & Khas & Pahit & Kecoklatan & 6,45 \\
\hline
\end{tabular}

Tabel 3. Hasil uji busa ekstrak Kamboja Merah

\begin{tabular}{cccc}
\hline Jenis Ekstrak & $\begin{array}{c}\text { Kode } \\
\text { Sample }\end{array}$ & Busa & $\begin{array}{c}\text { Tinggi Busa } \\
\text { (mm) }\end{array}$ \\
\hline Bunga Kamboja & A1 & Ada & 25 \\
& A2 & Ada & 10 \\
& A3 & Ada & 7 \\
& A4 & Ada & 10 \\
& A5 & Ada & 1 \\
\hline Daun Kamboja & B1 & Ada & 23 \\
& B2 & Ada & 13 \\
& B3 & Ada & 5 \\
& B4 & Ada & 5 \\
& B5 & Tidak Ada & - \\
\hline Batang Kamboja & C1 & Ada & 15 \\
& C2 & Ada & 12 \\
& C3 & Ada & 5 \\
& C4 & Ada & 5 \\
& C5 & Ada & 1 \\
\hline
\end{tabular}

Secara umum dari hasil pengujian terjadi busa yang menandakan bahwa dalam ekstrak kamboja merah mengandung saponin. ${ }^{5}$ Uji busa menunjukkan bahwa ekstrak air kamboja merah menghasilkan busa yang lebih tinggi dibandingkan pelarut lain dengan busa tertinggi dihasilkan dari bagian bunga. Pemilihan jenis pelarut berpengaruh pada hasil ekstraksi. Air merupakan pelarut yang memiliki kepolaran tertinggi sehingga memiliki daya melarutkan saponin lebih besar. Saponin memiliki sifat yang sangat larut dalam air, membentuk busa koloidal, dan memiliki sifat detergen yang baik. ${ }^{15}$ Berdasarkan hasil pengukuran busa diketahui bahwa ekstrak A1 memiliki busa tertinggi dibandingkan ekstrak $\mathrm{B} 1$ dan $\mathrm{C} 1$, sehingga diduga bahwa bagian bunga kamboja merah mengandung senyawa saponin paling tinggi dibandingkan bagian daun dan batang. Kandungan saponin yang terdapat pada ekstrak air kamboja merah dapat menurunkan tegangan permukaan. Tabel 4 menunjukkan hasil uji tegangan permukaan tiga bagian ekstrak air kamboja merah.

Ekstrak A1 yaitu ekstrak bunga kamboja merah dengan pelarut air 
diperoleh gambaran grafik penurunan tegangan permukaan ditunjukkan pada Gambar 1. Grafik menunjukkan nilai Critical Micelle Concentration (CMC) melalui perpotongan garis penurunan tegangan permukaan dengan garis konsentrasi ekstrak dimana nilai tegangan permukaannya relatif sama, kemudian diekstrapolasi sehingga diketahui pada konsentrasi tersebut terjadi CMC. Secara teori, CMC dapat terjadi dengan adanya penambahan surfaktan dalam larutan akan menyebabkan turunnya tegangan permukaan larutan. Setelah mencapai konsentrasi tertentu, tegangan permukaan akan konstan walaupun konsentrasi surfaktan ditingkatkan. Bila surfaktan ditambahkan melebihi konsentrasi ini maka surfaktan mengagregasi membentuk misel. Konsentrasi terbentuknya misel ini disebut Critical Micelle Concentration (CMC). Tegangan permukaan akan menurun hingga CMC tercapai. Setelah CMC tercapai, tegangan permukaan akan konstan yang menunjukkan bahwa antar muka menjadi jenuh dan terbentuk misel yang berada dalam keseimbangan. ${ }^{16}$

Gambar 1 diperoleh hasil pengukuran tegangan permukaan ekstrak A1, diperoleh persamaan garis : $\mathrm{y}=-1,2181 \mathrm{x}+$ 61,468 dan $y=-0,1507 x+52,273$ sehingga setelah dihitung perpotongannya diperoleh hasil $\mathrm{x}=8,61$. Dengan demikian nilai CMC untuk ekstrak air bunga kamboja merah (Plumeria rubra) pada konsentrasi $8,61 \%$.

Ekstrak B1 yaitu ekstrak daun kamboja merah dengan pelarut air diperoleh gambaran grafik penurunan tegangan yang ditunjukkan pada Gambar 2.

Tabel 4. Hasil uji tegangan permukaan ekstrak Kamboja Merah

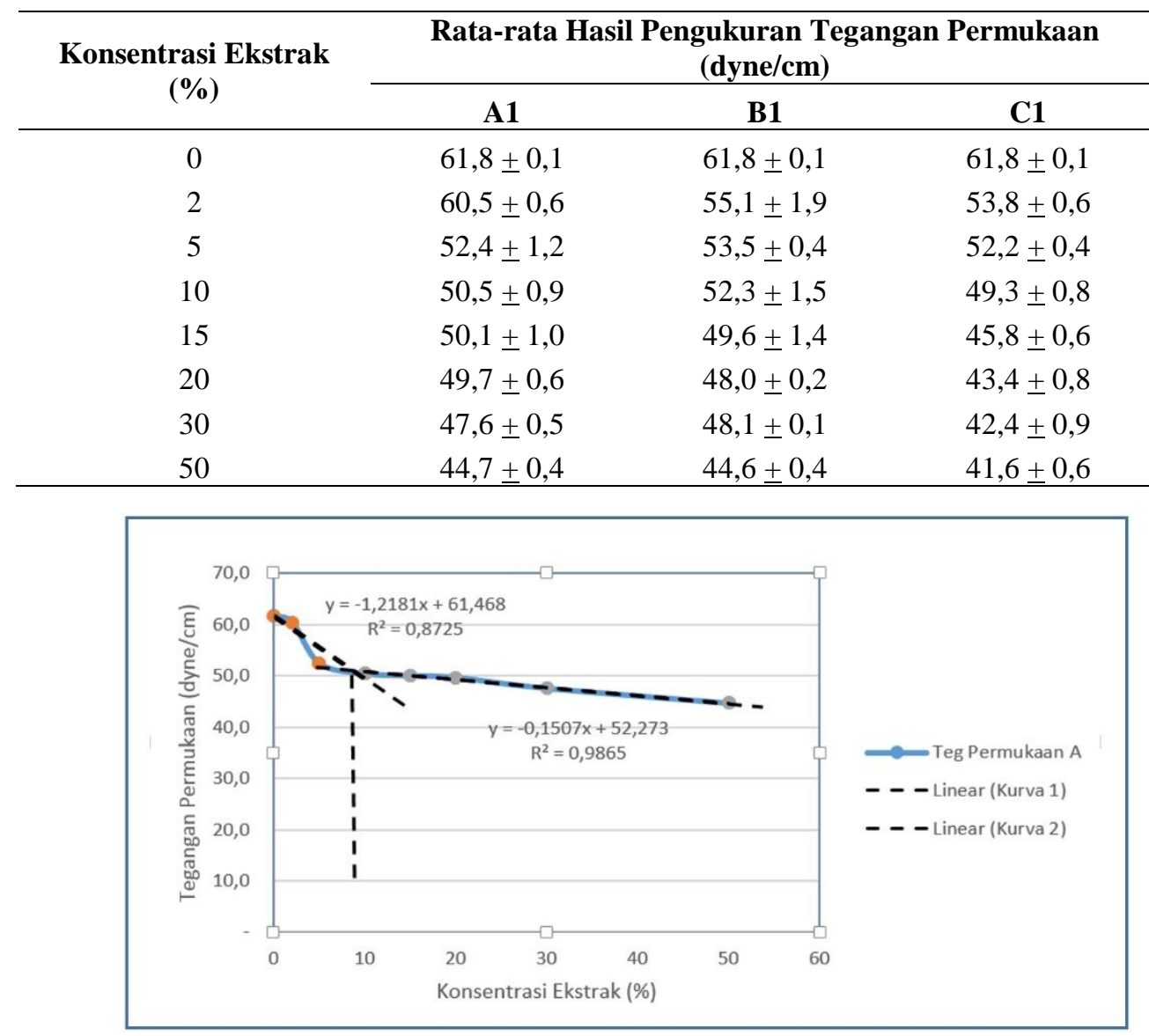

Gambar 1. Pengukuran Tegangan Permukaan Ekstrak Bunga Kamboja Merah (A1) 
Dari Gambar 2, hasil pengukuran tegangan permukaan ekstrak B1, diperoleh persamaan garis $\mathrm{y}=-0,6576 \mathrm{x}+58,669$ dan $\mathrm{y}=-0,1304 \mathrm{x}+51,333$ sehingga setelah dihitung perpotongannya diperoleh hasil $\mathrm{x}$ $=13,92$. Dengan demikian nilai $\mathrm{CMC}$ untuk ekstrak air daun kamboja merah (Plumeria rubra) pada konsentrasi 13,92\%

Kode ekstrak C1 yaitu ekstrak batang kamboja merah dengan pelarut air diperoleh gambaran grafik penurunan yang ditunjukkan pada Gambar 3. Gambar 3menunjukkan hasil pengukuran tegangan permukaan ekstrak $\mathrm{C} 1$, diperoleh persamaan garis $\mathrm{y}=-0,7815 \mathrm{x}+57,823$ dan $\mathrm{y}=-0,0571 \mathrm{x}+44,405, \quad$ sehingga setelah dihitung perpotongannya diperoleh hasil $\mathrm{x}$ $=18,52$. Dengan demikian nilai $\mathrm{CMC}$ untuk ekstrak air bunga kamboja merah
(Plumeria rubra) adalah pada konsentrasi $18,52 \%$

Hasil pengujian tegangan permukaan pada beberapa sampel ekstrak tanaman kamboja merah menunjukkan bahwa baik bagian bunga, daun dan batang dapat menurunkan tegangan permukaan. Hasil terbaik diberikan oleh ekstrak A1 yang berasal dari bagian bunga dan pelarut air $100 \%$, karena dengan nilai konsentrasi terkecil dapat memberikan nilai CMC dibandingkan dengan ekstrak lainnya. Berdasarkan hasil penelitian ini ekstrak bunga tanaman kamboja merah dapat dimanfaaatkan untuk formulasi sediaan kosmetika pembersih yang memerlukan bahan bersifat surfaktan yang dapat mengangkat kotoran sebagai efek fungsi pembersih.

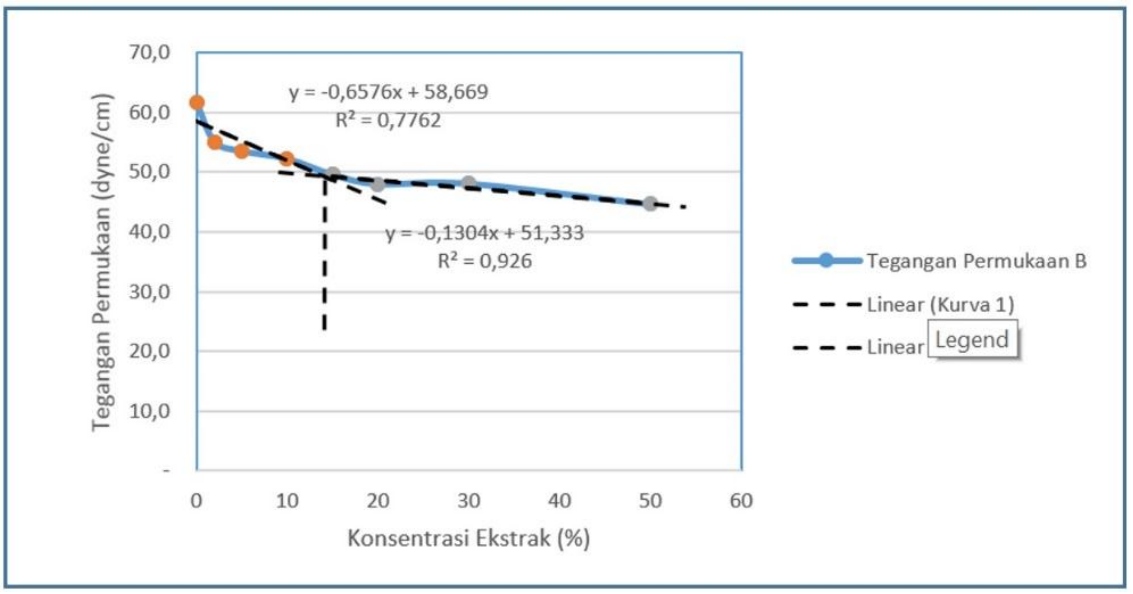

Gambar 2. Pengukuran Tegangan Permukaan Ekstrak Daun Kamboja Merah (B1)

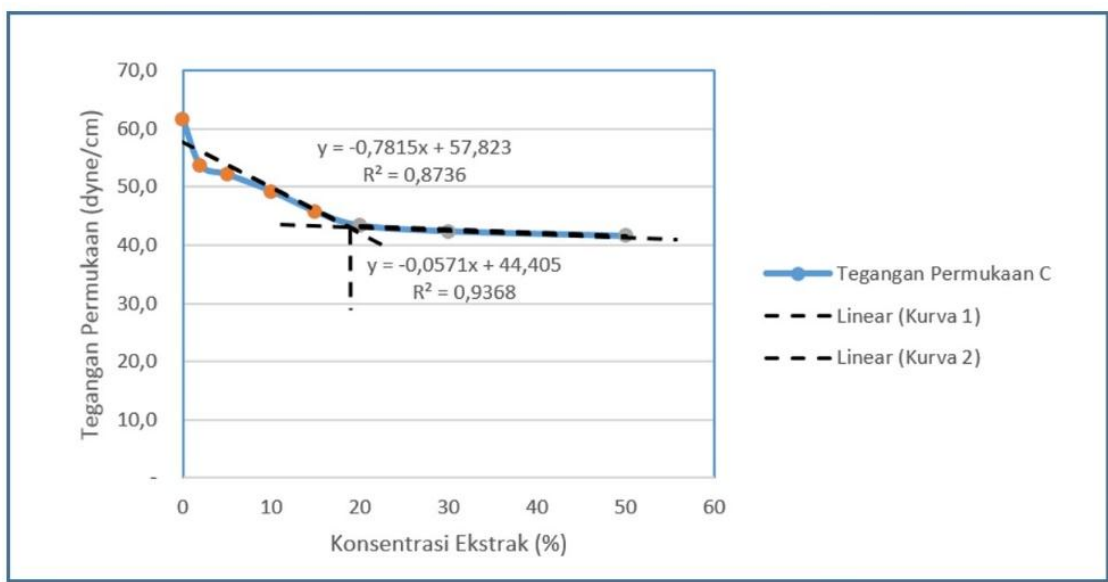

Gambar 3. Pengukuran Tegangan Permukaan Ekstrak Batang Kamboja Merah (C1) 


\section{KESIMPULAN}

Ekstrak bunga kamboja merah memiliki kandungan saponin yang mempunyai sifat dapat menurunkan tegangan permukaan dengan nilai $\mathrm{CMC}$ pada konsentrasi $8,61 \%$.

\section{SARAN}

Diperlukan penelitian lebih lanjut meliputi fraksinasi agar dapat diperoleh kandungan saponin yang lebih tinggi dari tanaman kamboja merah dan penentuan nilai Hydrophilic Lipophilic Balance (HLB) dari ekstrak tanaman kamboja merah.

\section{UCAPAN TERIMA KASIH}

Penulis mengucapkan terima kasih kepada Kepala Program Studi Magister Herbal, Fakultas Farmasi Universitas Indonesia atas dukungan dan bantuan sarana dan prasarana sehingga penelitian ini dapat berjalan dengan baik.

\section{DAFTAR RUJUKAN}

1. Dyck SV, Gerbaux P, Flammang P. Qualitative and quantitative saponin contents in five sea cucumbers from the Indian Ocean. Mar Drugs. 2010 Jan;8(1):173-89.

2. Martin MR, Rhein LD. Surfactants in cosmetics, second edition, New York : Marcel Dekker Inc, New York. 2008.

3. Farooque A, Mazumder A, Shambhawee S, Mazumder R. Review on plumeria acuminata. International Journal Of Research In Pharmacy And Chemistry. 2012; 1(2): 467-469

4. Wrasiati LP. Karakteristik dan toksisitas ekstrak bubuk simplisia bunga kamboja cendana (Plumeria alba) serta peranannya dalam meningkatkan aktivitas antioksidan enzimatis pada tikus sprague dawley (disertasi) . Denpasar: Universitas Udayana; 2011.

5. Surendra KR, Sharma, Kumar N. Pharmacognostical standardisation of plumeria acutifolia (poir) bark. International Journal of Pharmacy and Pharmaceutical Sciences. 2012 Dec;4 (4):54-57.

6. Sirisha K, Rajendra Y, Gomathi P, Madhavi M, Himabindu G, Aparna Y.(2014). Comperative phytochemical and pharmacological evaluation of flowers of Plumeria rubra L. F. Rubra and Plumerua rubra f. Lutea. British Biomedical Buletin. 2014;2(1):49-57.

7. Zaheer Z. Antimicrobial activity of essential oil of flowers of plumeria alba Linn (apocynaceae). International Journal of Pharmacy and Pharmaceutical Sciences. 2010;2(4): 155-57.

8. Ajit K, Indranil C, Arti S, Kopal. Extraction and evaluation of pharmacological activity of saponin extract of plumeria rubra leaves. Pharmocologyonline. 2009;1:969-974.

9. Shinde PR, Patil PS, Bairagi VA. Phytopharmacological review of plumeria species. Scholars Academic Journal of Pharmacy. 2014;3(2):21727.

10. Devprakash RT, Gurav S, Kumar S, Mani T. An review of phytochemical constituents \& pharmacological activity of plumeria species. International Journal of Current Pharmaceutical research.2012;4(1);16.

11. Suharto MAP, Edy HJ, Dumanauw JM. Isolasi dan identifikasi senyawa saponin dari ekstrak metanol batang pisang ambon (Musa paradisiaca var.sapientum L.). Pharmacon. 2012; 1 (2); 86-92. 
12. Departemen Keseharan RI. Farmakope herbal indonesia edisi I. Jakarta: Departemen Kesehatan; 2008.

13. Wijaya WH. Uji efektivitas sediaan tonik rambut ekstrak biji klabet (trigonela foenum-graecum 1.) pada proses pertumbuhan rambut (tesis). Depok:Universitas Indonesia; 2013.

14. Ghosh P. Surface tension. nptelchemical engineering-interfacial engineering. India: IIT: 2009.
15. Chapagain BP, Wiesman Z, Larvicidal activity of the fruit mesocarp extract of balanites aegyptiaca and its saponin fractions against aedes aegypti. Dengue Bulletin. 2015;29

16. Kowalsky SJ, Kulczynski K. Reduction of fractures in dried claylike materials due to specific surfactant, Chemical Engineering Research and Design, 2013;91(2), 25463. 